\title{
All about that Place: Tuning in to Community Radio - Listener Diary Accounts <a>
}

\author{
Catherine Wilkinson
}

Edge Hill University, Ormskirk, UK

Catherine.wilkinson@edgehill.ac.uk

Samantha Wilkinson

Manchester Metropolitan University, Manchester, UK

Samantha.wilkinson@mmu.ac.uk

\section{Introduction $<\mathrm{a}>$}

In this chapter we explore how music and sound connect people to the diverse places and spaces of everyday life, and are also responsible for place-making. Place-making refers to myriad, diffuse, everyday practices - including media-related practices (Couldry, 2010), through which proximities are organized and given meaning (Cante, 2015). Urry (2001, p. 4) acknowledges that 'various objects and mundane technologies ... sensuously extend human capacities into and across the external world'. We argue that radio is one such technology. Our focus lies in the corporeality of musical experience, the impact of rhythm (of songs) and pitch (of accents) on the body. Such data highlight how sound and music are meaningful ingredients in the microgeographies (that is, a focus concerned with a strict geographic localisation) of placemaking. We use more-than-representational theory, which is interested in what 'bodies and things' do (Thrift, 2008 p. 6), to examine how sound is meaningful, through the workings of emotion and affect. 
Using the case study of KCC Live, a youth-led community radio station based in Knowsley, neighbouring Liverpool, UK, we draw on data from listener diaries and follow-up interviews, as well as an autoethnographic listener diary kept by the first author. The focus of this chapter is methodological, as we advocate the usefulness of diaries to the production of knowledge that is felt, heard and embodied. While studies have made contributions to the research on sound and music using a more conventional ethnography and qualitative interviews, few have addressed the embodied and affective capacities of music and voice. This chapter aims to fill this deficit by using more-than-representational theory to 'get at' these aspects.

\section{Towards more-than-representational sonic geography <a>}

Non-representational geographies are concerned with the 'geography of what happens' (Thrift, 2008 , p. 2). Non-representational theory is therefore an attempt to capture the onflow of everyday life. We, following Lorimer (2005, p. 83), prefer the phraseology 'more-thanrepresentational' geography to 'get at' 'more-than-human, more-than-textual, multisensual worlds'. More-than-representational theory emphasizes the 'intercorporeality of bodies, affects and objects' (Evans et al., 2011, p. 337), and provides a means to consider bodies in an emergent, relational manner in terms of their ongoing reciprocity with the spaces they inhabit (Bissell, 2014). This framework is useful for studying the sonic world as it is corporeal; that is, the materiality of the world is fundamental to place-making, and sound can help us map out these relationships and connections.

Emotion and affect have become major themes for human geographical research (Pile, 2010). Emotions 'belong to an individual agent' (Horton and Kraftl, 2006, p. 79); they are personally experienced. More-than-representational theory adds an insistence on the significance of that which cannot (or cannot easily) be brought into representation - whether those representations 
are textual, linguistic, visual or otherwise (Thrift and Dewsbury, 2000). Meanwhile, affect refers to: 'intensities that are felt but not personal; visceral but not confined to an individuated body' (Whatmore, 2006, p. 604). It is a quality of life beyond cognition and it is always interpersonal (Pile, 2010). Though we acknowledge the multisensual world, as radio is a nonvisual or, as Crisell (1986, p. 3) famously termed it, 'blind' medium, we place emphasis on the sense of hearing and the activity of listening. It is for this reason that we now discuss listening and sonic affect.

\section{Listening and Sonic Affect $<\mathrm{b}>$}

Whilst hearing is the act of perceiving sound by the ear, listening is something you choose consciously to do (or not). Listening refers to the ways in which bodies (both human and morethan-human) respond to sound (Gallagher et al. 2016). Listening practices demand thinking not just in terms of representing places but as a practice that forges places through bodies (Smith, 2000). Cultural geographers increasingly approach the sonic realm in its affective and emotional, as opposed to representational, capacities (Gallagher, 2016; Revill, 2016).

Calling for a geography of voice and a politics of speaking and listening, scholars (Kanngieser 2012; 2014; Gallagher et al. 2016) have begun to explore the diverse characteristics of voices (including tone and volume), their affective and ethico-political forces, and how they make public spaces. Conceptualising sound as affect recognizes that 'sound does not just connect things; it changes them' (Kanngieser, 2015, 81). Human geographers have attended to the situated nature of sound's affectivity within particular social-political-material contexts, such as the home (Duffy and Waitt, 2013), cafes (Boyd and Duffy, 2012) and streets (Simpson, 2017). Few studies of sonic affect have focused on radio. This is surprising as sound is critical to radio programming, from the subtle intonation of a voice, to the ambient noise of an outdoor broadcast (Johnson, 2015). One exception is Kogawa and Kanngieser's (2013) discussion of 
'Convivial' radio in Japan. The authors argue that the micro-radio movement provides a compelling site for discussion when considering the intersections of affect, politics and communication, because of the communicational multi-directionality it sets into play. A further exception is Arkette's (2004) consideration of how different radio stations incorporate diverse modes of presentation. For instance, Radio 3 presenters talk 'in respectful tones and subdued inflections' conveying their musical knowledge, meanwhile Jazz FM showcases the 'fullbodied and breathy voice of the presenter' (Arkette, 2004, p. 165). Through the case study of KCC Live, this chapter examines how sound (specifically voice and music) is a meaningful ingredient in the microgeographies of place-making, through the workings of emotion and affect.

\section{Tuning in to KCC Live <a>}

KCC Live is a volunteer youth-led community radio station situated in Knowsley, neighbouring Liverpool, UK, and broadcasting across the Borough of Knowsley. Volunteers (typically aged 14-25 years) from the college and the wider community assume the role of presenters, producers, newsreaders, copywriters, segue-technicians and assistant managers. The station's target audience is 10-24 year-olds in the centre of the Borough (KCC Live, 2007). KCC Live positions itself as an 'exciting, non-elitist, highly-varied radio' (KCC Live, 2007, p. 4), which values and explores young people's musical tastes, opinions and daily lives, in ways that are relevant to them.

The station is committed to playing music that is not regularly played on commercial stations' playlists. Music aired predominantly falls into the following genres: Dance; Trance; Scouse House; Urban; Hip Hop; Trip Hop; Heavy Metal; 80s and 90s; RnB; Chart; Classic Rock; Rock Pop; Alternative; and Acoustic. The station also airs music by local unsigned artists. Of the daytime output broadcast on KCC Live, 24 percent is speech (KCC Live, 2013). This speech 
includes: current affairs; talk shows; news; quiz shows; entertainment; sports coverage; and general free 'personality' speech time.

\section{Methods <a>}

This chapter emerges from a larger research project undertaken by the first author (see Wilkinson, 2015) which employed a range of methods, including 18 months of observant participation at KCC Live (see Wilkinson, 2017 for further discussion of this method), more than 95 semi-structured in-depth interviews with volunteers and staff, two focus groups; a listener survey which generated 460 responses; listener diaries with five listeners; and followup listener diary interviews. These methods enabled engagement with the broad range of communities (listeners, staff and volunteers) involved in KCC Live. In this chapter, we focus on data arising from listener diaries, including the first author's own listener diary, and followup interviews with diary respondents. By advocating the use of listener diaries, we are responding to Gallagher, Kanngieser and Prior's (2016) call for expanding listening in human geography. The listener diary method achieves this by enabling diarists to reflect on the embodied experiences of radio listening.

\section{Listener diaries and diary-led interviews $<\mathrm{b}>$}

Five listener diary participants were recruited after providing their contact details on a listener survey and consenting to be contacted. The respondents were relatively varied in age, gender and demographics: a female student at a local private school; a father of a KCC Live volunteer; a male university student; a young mother living in Cornwall; and a male young person who was not in education, employment or training. Each listener diarist was provided with a guidance sheet to assist with the completion of entries. This included prompts such as 'What was happening on air whilst you were listening?', 'How did you feel while you were 
listening?', 'Was there any mention of the community or local issues? How did this make you feel?'. Individually, participants and the researcher documented their listening habits (for example when they listened, for how long, on what platform) and reflections of on-air content over a period of five months, offering longitudinal insights into their listening experiences. Solicited diaries have become an integral ethnographic technique in human geography (Latham, 2003). The usefulness of diaries as a methodological tool is attributed to their ability to facilitate access to emotional spaces and situations, typically beyond the researcher's reach (Morrison, 2012). While Crang (2003, p. 501) positions solicited diaries as useful for eliciting the 'felt, touched and embodied constitution of knowledge', we advocate the usefulness of diaries to the production of knowledge that is 'felt, heard and embodied'. Using diary methods supports the ability to derive 'emotionally poignant and powerful' accounts from research (see Davidson et al., 2005, p. 3). This is because it privileges people's expressed emotional experiences, and treats their accounts as 'open, honest and genuine' (Pile, 2010, p. 8). Beneficially, as the solicited diary is a portable method (Bijoux and Myers, 2006), it can engage with the variety of spaces afforded by the portability of radio, such as the home, college/university/work and public transport.

Follow-up interviews were used to gain deeper insight and context into the diary content. In these diary-led interviews, the diaries served as memory prompts. Interviews provide an effective medium through which respondents can articulate their embodied practices (Hitchings, 2012) and can identify affective bodily capacities (Fox and Alldred, 2015). Pile (2010, p. 11) argues that gaining a sense of the emotional or affectual experiences and undercurrents of life involves 'a kind of peeling away of superficial and glib responses'. Though we are not saying that diaries provide superficial and glib responses, we argue that the diary-led interviews in this study enabled a more detailed and intimate story to be uncovered. 
Through advocating use of diaries and interviews, we support other scholars (Carolan, 2008, p. 412; Latham, 2003) in arguing that traditional methods can be adapted and employed to 'get at the buzzing world of the more-than-representational'.

A thematic approach to analysis was adopted using emotion, affect, voice and music as part of categorising and classifying the data. After typing up each of the handwritten diaries, the first author read through the data set multiple times, separating the data into smaller, significant parts. She labelled each of these smaller parts with a code and then compared each new segment of data with the previous codes that had emerged. This ensured that similar data were labelled with the same code. The first author then undertook a process of abstracting, whereby she condensed the codes into deeper conceptual constructs. She continued this until all coded sections were saturated.

\section{Listening bodies < $<>$}

Research in emotional geography conceptualizes the body as a site of feeling and experience (Pile, 2010). Through the listener diaries we found that music is heard, and judged by bodies, as 'appropriate' only if it fits with that individual's everyday life (Anderson 2005). Negative judgments made about music occur due to the mismatch between the materialities of music and the manner in which 'as emotions ebb and flow in experience, the person is absorbed into and withdraws from given regions and features of the world' (Katz 1999, p. 335). For example, Maisy describes how she judges the fit of the music through embodied affections: 
Sometimes if I'm really down, I want to waddle in being sad, so I turn up the love songs - like they [KCC Live] play a lot of Adele ${ }^{1} \ldots$ When I'm really down I have to skip the Rock show, turn the radio off or right down - that stuff is too heavy, and not what I need...When I'm happy I like upbeat songs, like pop and chart stuff and tend to crank the volume up.

(Maisy, 19, listener diary interview)

In the above quote, arguably the rhythm (for instance of 'heavy' rock music) affected Maisy, whilst she also used rhythm and volume to affect herself, that is, to enhance or diminish certain emotions. This relates to Bull's $(2005 ; 2007 ; 2013)$ research into how users of music devices may be aware of their mood and may strategically plan to enhance or change that mood (see also Skånland, 2011; 2013). Another example of this came through in Eddie's listener diary:

I became rather bored whilst listening to the show, with hardly any 'rock' music being played during the 'rock' show. The presenter didn't speak to his listeners once whilst ... after just 25 minutes of listening, I turned the radio off.

(Eddie, 21, listener diary, 17 March 2014)

Eddie tells us something of the corporeal pleasures (or not) of listening (Duffy and Waitt, 2011). Arguably, in Eddie's account turning the radio off is a defiant act of boredom. Importantly, it provides insight into the strategies that listeners use, not only to manage their sonic environments (Prior, 2014), but also for affect regulation (Skånland, 2013); that is managing moods and emotions. Other such actions reported by listener diarists include turning the volume up or down, and changing station.

\footnotetext{
1 Adele Laurie Blue Adkins is an English singer-songwriter, renowned for singing ballads.
} 
Also interesting to emerge from the list3dv oyd, 2014). Boyd (2014) uses the term dancing mobilities to refer to the embodied and representational practice of dancing. Take the following excerpts:

I was listening to KCC Live at bath time. Me and Kayden [Michelle's two year old son] were bopping to the music. I picked Kayden up and put him up on the toilet seat and he bopped some more. We were smiling and laughing and danced until the song stopped and the presenter started talking.

(Michelle, 24, listener diary, 12 May 2014)

The presenter played Mr Probz ${ }^{2}$ new song "Waves". I squealed when it came on because I was so excited to hear it. Having listened to KCC Live for a number of months now, I have learnt how frequently (or infrequently) songs are played/repeated throughout the day. I had been waiting for this song with anticipation all morning. I turned up the volume dial and I felt my foot stomping and my shoulders swaying as the beat took over.

(First author's listener diary, 22 February 2014)

Michelle's discussion of how her and Kayden were 'smiling and dancing' relates to how dancing is 'emotionally charged' (Jones, 2005, p. 814). Interestingly, despite the embodied, emotional dimensions of dance experienced by Michelle whilst the song was playing, Michelle notes how herself and Kayden stopped dancing when the presenter started talking, reflecting how affect is not only continuously emerging, but also fleeting (Müller, 2015). Further, in the first author's listener diary she reports 'swaying' and 'stomping' along to a song that she had

\footnotetext{
${ }^{2}$ Dennis Princewell Stehr, better known by his stage name Mr Probz, is a Dutch singer, musician and actor
} 
been waiting to be played. She was therefore affected by the music, producing the "visible conduct' (Müller, 2015, p. 411) of dancing. These accounts of visceral reflexes relate to Gallagher's (2016, p. 43) argument that sound, as a form of affect, can move bodies, as a 'vibration physically pushing and pulling their material fabric'.

\section{The microgeographies of place-making <a>}

Herein, we turn to discuss the microgeographies of place-making in relation to radio listening and hearing. The sonic capacity of KCC Live, as a local radio station, can be seen as a placemaking device, whereby emotion, affect and sound combine to affect the meaning people attribute to places. In the following excerpts from Michelle's listener diary, we can see how listening is a process of actively creating and attributing meaning to a place:

Gideon [presenter from Manchester] made a joke today - something about people packing their things up \& when Benno [presenter from Liverpool] asked why, he said they had heard there were Scousers visiting! I suppose there is a stereotype that people from Liverpool are thieves . . . but I know everyone is an individual! Thought it was a bit bad of Gideon but I know it was said with tongue in cheek. Hope Liverpool isn't full of criminals anyway!

(Michelle, 24, listener diary, 13 February 2014)

Gideon was doing the travel \& said don't go near Kirkdale (wherever that is) but he said it's Kirkdale so I don't go there usually! It sounds like a rough area of Liverpool.

(Michelle, 24, listener diary, 10 February 2014)

Michelle lives in Cornwall and previously listened to Atlantic FM, a local station in Cornwall, before a takeover by radio network Heart. Michelle said regarding the takeover: 'I was a very involved listener \& often mentioned [on air by radio presenters]. I was heartbroken!'. In a follow-up interview, Michelle told how she came to feel 'in place' through listening to stories of Liverpool and Knowsley (such as those reflected on in her diary above), specifically those 
that were delivered in a Scouse accent. The Scouse accent of presenters shaped Michelle's emotional encounters with space and place (see Bull, 2005; 2007; 2013), specifically Knowsley. For Michelle then, the presenters' accents functioned not only as an index of human presence, but also served to locate the station and provide the 'map of 'local' life' (see Berland, 1990, p. 191).

While, for Michelle, the Scouse accents of presenters had the capacity to connect disparate bodies (LaBelle, 2006), making her feel 'in place', for other listener diarists, there was a sense of 'disconnect':

If someone has a really thick Scouse accent I tend not to listen, just turn it down . . . People need to be articulate, irrespective of their regional accent . . . for me there's that disconnect, it doesn't work

(Eddie, 18, listener diary interview)

I listened to the Drive Time show today, and there was a stand-in presenter. Her voice was so screechy that it grated on me. I have a strong Scouse accent, and all of my friends do, but listening to it on the radio was really cringeworthy, it was so high pitch, and it made me not want to listen.

(Maisy, 19, listener diary, 21 June 2014)

The above quotations from Eddie and Maisy demonstrate the role of timbre in voice in assisting/enabling the body to feel 'at home', or not (Duffy and Waitt, 2013). Following Duffy and Wait (2013, p. 470), this is because sound coheres subjectivities, places and a sense of 'togetherness'. However, the above accounts demonstrate that sound also has the potential to repel and exclude; although Maisy reports possessing a strong Scouse accent, listening to the accent of the presenter on KCC Live repelled her, whilst Eddie (who possess a Southern 
accent), confesses to turning down the volume when a presenter with a thick Scouse accent is speaking. These responses provide some insight into the social construction of identity and 'appropriate' voices for radio. Mugglestone (1995), found a similar set of relationships between voice and place, and in considering accent as a social symbol, reveals that, for listeners in his study, the integrity of the news was compromized when delivered in Yorkshire tones.

In addition, what also emerged through the listener diaries was how sounds can connect a person's sense of self to a larger community (van Dijk, 2006), and can trigger memories of past events or far away locations (Duffy and Waitt, 2011). Arguably, this is because the music playlist produced by radio stations demarcates the present from the immediate and distant past; with its new hits, its repetitions and recyclings, its rising and falling stars (Berland, 1990). Another way of viewing this - and often used in music therapy studies - is to consider the ways music is specifically linked to memory. For instance, in studies of people with dementia they are 'awakened' when listening to music of their past (Robertson-Gillam, 2011). Take the following excerpt from the first author's listener diary:

KCC Live played a song today that I hadn't heard them play before, "Buck Rogers" by Feeder, and it immediately took me back to my teenage years, growing up in Sidmouth, a small town in Devon, and pre-drinking with my friends. Listening to this song made me feel nostalgic, happy and a little sad at the same time. I did wonder, however, whether anyone else in Knowsley would have a similar emotional connection to that song.

(First author's listener diary, 22 February 2014)

"Buck Rogers" contains lyrics about getting a house in Devon and drinking cider from a lemon. As can be seen from the first author's listener diary, the lyrics affected her, transporting her to a place more than 250 miles away from Knowsley, where the first author had these experiences 
ten years earlier. Here, the first author noted that the impact came through the lyrics, with the sound and timbre perhaps providing other impacts not readily discerned. Lyrical and experiential connections with place, then, reflect music's capabilities to transport us across time and distance. Importantly, this reminds us that feelings of affinity are not always within touching distance (Lorimer, 2005). This relates to Carvalho and Tolia-Kelly's (2001) discussion of how it is the remembered feel of, as well as picturable feelings for, a landscape that matter in our intimate connections to place.

\section{Conclusion $<a>$}

Through the case study of community radio station KCC Live, this chapter has examined how sound is a meaningful ingredient in the microgeographies of place-making through the curation of accents and songs associated with place. We promoted listener diaries as a method of data collection well suited to harnessing the experiences of radio listening, capturing the production of knowledge that is felt, heard and embodied, and in facilitating access to emotional spaces and situations.

We argue that a focus on the processes of sound requires us to take up new ways of thinking about embodiment and sound, because it draws attention to ourselves not as separate entities situated within a place, but as embedded in and through the human and non-human elements of that space. Yet, this also raises 'the thorny issue of how to explore and experiment' with what sound is and how it works (Wood et al. 2007, p. 868). We used more-than-representational ideas to collect data, aiming to 'get at' the corporeal nature of the sonic world. We argue that more-than-representational theory, in particular the tools of emotion and affect, offers a means through which to do this through its considerations of fleeting experiences, feelings and 
encounters that, while often banal and unexceptional, are integral to shaping our everyday worlds. 


\section{References}

Anderson, B (2005), 'Practices of judgement and domestic geographies of affect', Social \& Cultural Geography, 6 (5), 645-659.

Arkette, Sophie (2004), 'Sounds like city', Theory, Culture and Society, 21 (1), 159-168.

Berland, J (1990), 'Radio space and industrial time: Music formats, local narratives and technological mediation', Popular Music, 9 (2), 179-192

Bissell, D (2014), 'Encountering stressed bodies: Slow creep transformations and tipping points of commuting mobilities', Geoforum, 51, 191-201.

Bijoux, D. and J. Myers (2006), 'Interviews, solicited Diaries and photography: 'New' ways of accessing everyday experiences of place', Graduate Journal of Asia-Pacific Studies, 4 (1), 44-64.

Boyd, C. and M. Duffy (2012), 'Sonic geographies of shifting bodies', Interference: A Journal of Audio Culture, 1, 1-7.

Boyd, J (2014), '“I go to dance, right?': Representation/sensation on the gendered dance floor', Leisure Studies, 33 (5), 491-507.

Bull, M (2005), 'No dead air! The iPod and the culture of mobile listening', Leisure Studies, 24 (4), 343-55.

Bull, M (2007), Sound Moves: iPod Culture and Urban Experience. New York: Routledge.

Bull, M (2013), 'iPod use: An urban aesthetic of sonic ubiquity', Continuum: Journal of Media \& Cultural Studies, 27 (4), 495-504. 
Cante, F (2015), 'Place-making, media practices and orientations. Exploratory connections between communications geography and Sara Ahmed's critical phenomenology', Sociologica, $9(3), 0-0$.

Carolan, M .S (2008), 'More-than-representational knowledge/s of the countryside: How we think as bodies', Sociologia Ruralis, 48 (4), 408-422.

Carvalho, M. and D. Tolia-Kelly (2001), 'Intimate distance: Fantasy islands and English lakes', Ecumene. 8 (1), 112-119.

Couldry, N. (2010), Theorising media as practice. In Bräuchler, B. and J. Postill (eds), Theorising Media and Practice, Oxford: Berghahn.

Crang, M (2003), 'Qualitative methods: Touchy, feely, look-see?' Progress in Human Geography, 27 (4), 494-504.

Crissell, A (1986), Understanding Radio. London: Routledge.

Davidson, J., L. Bondi and M. Smith (2005), Emotional Geographies, Ashgate: Aldershot. Duffy, M. and G. Waitt (2011), 'Sound diaries: A method of listening to place', Aether: The Journal of Media Geography, 7, 119-136.

Duffy, M. and G. Waitt (2013), 'Home sounds: Experiential practices and performativities of hearing and listening', Social \& Cultural Geography, 14 (4), 466-481.

Evans, B., R. Colls. and K. Hoerschelmann (2011) “Change4Life For Your Kids': Embodied Collectives and Public Health Pedagogy', Sport, Education and Society, 16 (3), 323-341.

Fox, N. J. and F. Alldred (2015), 'New materialist social inquiry: Designs, methods and the research assemblage', International Journal of Social Research Methodology, 18 (4), 399-414. Gallagher, M (2016) 'Sound as affect: Difference, power and spatiality', Emotion, Space and Society, 20, 42-48. 
Gallagher, M., A. Kanngieser and J. Prior (2016), 'Listening geographies: Landscape, affect and geotechnologies', Progress in Human Geography, 41 (5) 1-20.

Hitchings, R (2012), 'People can talk about their practices', Area, 44 (1), 61-67.

Horton, J. and P. Kraftl (2006), 'What else? Some more ways of thinking and doing 'Children's Geographies', Children's Geographies, 4 (1), 69-95.

Kogawa, T. and A. Kanngieser (2013), A micro-history of 'convivial' radio in Japan. A conversation with Tetsuo Kogawa with an introduction by Anja Kanngieser, Parallax, 19 (2), $85-94$.

Johnson, P (2015), 'Editor's remarks: Sound matters across the world: Rehearing radio as an extension of practice and potential', Journal of Radio \& Audio Media, 22 (1), 1-2.

Jones, P (2005), 'Performing the city: A body and a bicycle take on Birmingham, UK', Social and Cultural Geography, 6 (6), 813-830.

Kanngieser, A (2012), 'A sonic geography of voice: Towards an affective politics', Progress in Human Geography, 36 (3), 336-353.

Kanngieser, A (2014), 'A proposition toward a politics of listening (geographies and atmospheres)', paper presented at the Invisible Places conference, Viseu, Portgugal, 18-20 July 2014.

Kanngieser, A (2015), 'Geopolitics and the anthropocene: Five propositions for sound', Geohumanities, 1 (1), 80-85.

Katz, J (1999), How Emotions Work, Chicago: Chicago University Press. 
KCC Live (2007), Public Sections of Hywel Evans' Application to Ofcom for a Community Radio Licence on behalf of Mission Need Ltd and KCC Live. pp. 1-64.

KCC Live (2013), 'Key Commitments Annual Report', accessed 30 November 2017 at www.kcclive.com/docs/cr162/CR162AR2013.pdf

Labelle, B (2006), Background Noise: Perspectives on Sound Art, London: Continuum.

Latham, A (2003), 'Research, performance, and doing human geography: Some reflections on the diary-photograph, diary-interview method', Environment and Planning A, 35 (2), 19932017.

Lorimer, H (2005), 'Cultural geography: The busyness of being 'more-than-representational', Progress in Human Geography, 29 (1), 83-94.

Morrison, C. A (2012), 'Solicited diaries and the everyday geographies of heterosexual love and home: Reflections on methodological process and practice', Area, 44 (1), 68-75.

Müller, M (2015), 'More-than-representational political geographies'. In Agnew, J., V. Mamadouh., A. Secor. and J. Sharp (eds) The WileyBlackwell Companion to Political Geography. Wiley-Blackwell: Oxford, pp. 409-423.

Mugglestone, L (1995), “Talking Proper”: The Rise of Accent as Social Symbol. Oxford: Clarendon Press.

Pile, S (2010), 'Emotions and affect in recent human geography', Transactions of the Institute of British Geographers, 35 (1), 5-20.

Prior, N (2014), 'The plural iPod: A study of technology in action', Poetics, 42 22-39.

Revill, G (2016) 'How is space made in sound? Spatial mediation, critical phenomenology and the political agency of sound', Progress in Human Geography, 40 (2), 240-256.

Robertson-Gillam, K (2011), 'Music therapy in dementia care', In H. Lee and T. Adams (eds), Creative Approaches in Dementia Care, New York: Palgrave Macmillan. pp. 91-109. 
Simpson, P (2017), 'Sonic affects and the production of space: 'Music by handle' and the politics of street music in Victorian London', Cultural Geographies, 24 (1), 89-109.

Skånland, M. S (2011), 'Use of MP3 players as a coping resource', Music and Arts in Action, $3(2), 15-33$.

Skånland, M. S (2013), 'Everyday music listening and affect regulation: The role of MP3 players', International Journal of Qualitative Studies on Health and Wellbeing, 8 (1), 20595.

Smith, S. J (2000), 'Performing the (sound) world', Environment and Planning D: Society and Space, 18 (5), 615-637.

Thrift, N (2008), Non-Representational Theory: Space, Politics, Affect, London: Routledge.

Thrift, N. and J-D. Dewsbury (2000) 'Dead geographies - and how to make them live', Environment and Planning D: Society and Space, 18 (4), 411-32.

Truax, B (2000), Acoustic Communication, Connecticut: Ablex Publishing.

Urry, J (2001), 'Globalising the tourist gaze', accessed 28 November 2017 at www.comp.lancs.ac.uk/sociology/papers/Urry-Globalising-the-Tourist-Gaze.pdf.

van Dijk, J (2006), 'Record and hold: Popular music between personal and collective memory', Critical Studies in Media Communication, 25 (5), 357-374.

Wilkinson, C (2015) Connecting Communities through Youth-led Radio (unpublished Doctoral thesis). University of Liverpool.

Wilkinson, C (2017), 'Going 'backstage': Observant participation in research with young people', 15 (5), 614-620. 
Whatmore, S (2006), 'Materialist returns: Practising cultural geography in and for a more-thanhuman world', Cultural Geographies, 13 (4), 600-609.

Wood, N., M. Duffy and S.J. Smith (2007), 'The art of doing (geographies of) music', Environment and Planning D: Society and Space, 25 (5), 867-889. 